\title{
2015 año de las neurociencias 2015 Neuroscience year
}

$\mathrm{L}$ a Sociedad de Neurología Psiquiatría y Neurocirugía ha declarado el 2015, año de las Neurociencias. Existen momentos significativos en las instituciones y para SONEPSYN la postulación al Congreso Mundial de Neurología 2015 en Santiago, representa el mayor desafío de nuestra Sociedad en mucho tiempo.

Pensamos que la presencia de connotados científicos en noviembre de 2015 debería ser precedido por un período de actividad científica donde todos los centros docentes y de investigación de Chile muestren su quehacer en esta área de la ciencia, tanto entre la comunidad científica como a todo el país. Si bien, los acontecimientos políticos y sociales parecen preeminentes en algunos momentos de la historia, sólo son circunstanciales y la ciencia es lo perdurable y particularmente las neurociencias, que adquieren cada vez más significado en la vida de la Humanidad.

No es casual que el premio "Príncipe de Asturias de las Ciencias" de Mayo de 2011, haya sido concedido a neurocientistas. Estos investigadores fueron reconocidos por la demostración de la regeneración de neuronas en el cerebro (Dr. Joseph Altman y Dr. Arturo Álvarez-Buylla), y por el descubrimiento del "Sistema en Espejo" (Dr. Giacomo Rizzolatti). El Sistema en Espejo es una condición mágica del cerebro de los primates, que permite al observador que con sólo ver el movimiento en otro sujeto "encienda" el área motora del cerebro del observador, que tiende a imitar mentalmente lo observado. Se supone que este mecanismo automático de imitación constituye la primera etapa de la comunicación y del lenguaje corporal, que dio sentido a gestos de cariño o de amenaza. Usamos este sistema en el aprendizaje de movimientos complejos, como el baile y los deportes. En base al automatismo del sistema, se explica la conducta imitativa de los monos y de los humanos en las actividades masivas.
El estudio de las neurociencias involucra todo aquello que sentimos como esencialmente humano, incluida la soledad del hombre como las actividades gregarias, así como los sentimientos y la pasión que desencadenan los programas masivos de televisión. La neurociencia abarca el estudio del modo y especialmente del por qué de las conductas. La neurociencia está en todo aquello que tenga relación con el cerebro. De allí el desarrollo de las distintas ramas de esta ciencia, que abarca lo biomolecular y lo conductual, la neuroanatomía y la neuroquímica, el amor y el odio. El motivo y la existencia de SONEPSYN se sustentan en la investigación y la difusión de las actividades normales y patológicas del cerebro.

La neurociencia busca comprender al hombre en su dimensión biológica, explicando el funcionamiento del sistema nervioso en sus detalles más íntimos. Así como la expresión de distintos neurotransmisores en diversos momentos y de las conexiones cerebrales que hacen de cada hombre un ser singular y único. Nada es más importante para acercarnos a entender lo que somos que las neurociencias.

Como dijimos, SONEPSYN fue creada para contribuir a la difusión de las ciencias del cerebro. Esta ciencia que nació con el hombre como ser dotado de reflexión y curiosidad y se consolidó cuando los primeros filósofos acuñaron el "conócete a ti mismo" para dar a entender que la base del saber está en comprender lo que somos.

El año 2015 debe transformarse en un festival del conocimiento para nuestros compatriotas, queremos lograr que cada habitante en cualquier rincón de Chile comprenda el significado de las neurociencias. Esta tarea será posible con la contribución de cientos de cultores e investigadores de las ciencias del cerebro. Hemos pensado que cada región, cada universidad y cada escuela desarrolle programas de manera independiente con el apoyo 
de SONEPSYN para coordinar y asistir en lo que sea necesario desde el punto de vista académico, para lograr que los trabajos de investigación y el conocimiento de la neurociencia llegue a todos.

La evolución y el crecimiento de nuestro cerebro ha sido el modo de comprender parcialmente su funcionamiento. La inteligencia que, siendo única en cada ser humano es también colectiva, nos ha permitido explorar el átomo, sumirnos en el espacio sin fin y acercándonos a Dios.

El origen reconocible de nuestra cultura son los griegos quienes, no siendo los creadores del saber, supieron organizar, consolidar y recrear el conocimiento que heredarnos asociado a un profundo sentimiento religioso. Si bien ellos eran politeístas por el desarrollo de su cultura, no significa que fueran menos creyentes que nosotros, sino que al contrario confiaban plenamente en sus dioses. Entre ellos los templos ocupaban los lugares más selectos y prominentes de sus ciudades. Junto a su fe y a la creación de ciencia, definieron conductas éticas que aún nos rigen y que no fueron producto del azar, sino que la consecuencia del valor que daban a las personas y a su estructura social. El exilio era un castigo máximo equivalente a la pena de muerte. Sabemos que Sócrates fue condenado al exilio por su desarraigo religioso y su impiedad. Él prefirió el suicido al exilio y bebió la cicuta. Sin embargo, al margen del pensamiento socrático que heredamos, también es válida la importancia que la sociedad griega daba a las instituciones que las sustentaban. Para ellos no había sociedad posible sin dioses.

Así como los griegos concebían su sociedad en armónica relación con sus dioses, la armonía de nuestra sociedad debiera apoyarse en el íntimo conocimiento de la Humanidad. En este contexto, la neurociencia nos ha permitido acercarnos a entender a la dinámica de los hombres. Siempre se ha creído que los factores económicos son la clave de sociedades más perfectas. Yo creo que la perfección está en el conocimiento del hombre y de la neurociencia con todo su potencial.

Luis Cartier R. Editor 